\title{
A NECESSIDADE DE UMA AVALIAÇÃO MULTIDIRECIONAL NO ENSINO JURÍDICO CONTEMPORÂNEO
}

\author{
Denise Almeida de Andrade ${ }^{1}$ \\ Letícia Prazeres Falcão ${ }^{2}$
}

\begin{abstract}
RESUMO
A avaliação dialoga com a desafiadora atividade do ensino: aferir o que e em que medida mudou na compreensão do discente sobre determinado assunto. Recentemente, se intensificaram discussões sobre a necessidade do ensino jurídico ser próximo da realidade. Não se avalia para obtenção de status de aprovação ou reprovação, mas para a construção de conhecimento crítico. Permitir essa movimentação é tornar o ensino jurídico algo que alcance além daqueles alunos, é fazer com que edificações cheguem aos docentes, discentes e coordenações. $O$ artigo utiliza da revisão bibliográfica, onde busca demonstrar que a avaliação multidirecional no ensino jurídico é ferramenta útil.
\end{abstract}

Palavras-chave: Avaliação; Ensino Jurídico; Protagonismo discente; Docente; Educação

\section{THE NEED FOR MULTIDIRECTIONAL EVALUATION IN CONTEMPORARY LEGAL EDUCATION}

\begin{abstract}
The assessment dialogues with challenging teaching activity: assessing what and to what extent it has changed in the understanding of the student on a given subject. Recently, discussions about need for legal education to be close to reality have intensified. It is not evaluated for obtaining approval or disapproval status, but for construction of critical knowledge. To allow this movement is to make legal education something that reaches beyond those students, it is to make buildings reach teachers, students and pedagogical coordinators. The article uses bibliographic review, where it seeks to demonstrate multidirectional assessment in legal education is useful tool.
\end{abstract}

Keywords: Evaluation; Legal Education; Student protagonism; Teacher; Education

\section{INTRODUÇÃO}

Tratar de ensino jurídico no Brasil demanda entender que desde formatação dos primeiros cursos de Direito no Brasil, ainda no Império, forjou-se uma prática na qual a

\footnotetext{
${ }^{1}$ Professora do Programa de Mestrado em Direito da Unichristus. Pós doutora em Direito Político e econômico pela Universidade Presbiteriana Mackenzie 2016/2019 (PNPD-CAPES). Doutora (PROSUP-PRODAD) e Mestre em Direito Constitucional pela Universidade de Fortaleza - UNIFOR (2016). Email:andradedenise@hotmail.com

${ }^{2}$ Aluna do Programa de Mestrado em Direito da Unichristus. Especialista em Direito da Família, Infância e Juventude pelo Centro Universitário Dom Bosco - UNDB. Mediadora e Conciliadora pelo Tribunal de Justiça do Maranhão. Email: leticiaprazeres@outlook.com.br
} 
dogmática, a hierarquia entre os sujeitos (docentes e discentes), o positivismo e uma certa distância das demandas sociais se fez presente. Nesse contexto, o momento da avaliação, tido talvez como o mais importante dentro da perspectiva acima apontada, existe para aferir o que foi incorporado ao repertório do/a discente naquele dia e horário previamente estabelecidos, atribuindo notas.

A avaliação, de fato, compõe o processo educacional, contudo, deveria ser entendida como uma continuidade do processo de aprendizagem, que dialoga com o que foi discutido e construído, que não se resume a único dia e hora; liga-se mais ao sistema de ensino e a quem lhe integra, do que a um momento final de um ano ou semestre letivo. Entendemos que se avalia não somente para aferir uma suposta captação de conteúdo, mas para sentir a medida dos acertos e equívocos das escolhas feitas no presente, as quais podem refletir nas ações a serem praticadas no futuro.

Estar-se-á diante de um trânsito paradigmático no qual o ensino jurídico também passa por revoluções, mudanças que vão desde as configurações de salas de aula até a forma como são vivenciadas a teoria e a prática, a inserção da interdisciplinaridade nos fluxogramas e projetos pedagógicos dos cursos de graduação, o incentivo à criticidade e aproximação de demandas reais, e mesmo o uso da tecnologia nessa aprendizagem. É de fato, uma luta constante entre a carga histórica que a educação jurídica carrega e a urgência de uma renovação de dentro para fora, de modo a se fazer em consonância com as novas profissões, novas metodologias, novos conteúdos e principalmente, com as novas gerações de alunos.

Tornar a avaliação um elemento multidirecional dentro do ensino jurídico contemporâneo é quebrar a noção de que avaliar é uma imposição, é uma manifestação unilateral de poder entre os sujeitos do processo de aprendizagem. É em verdade um passo para sentir e não aferir de que maneira as transformações e escolhas políticas educacionais se fazem adequadas ou não mediante todo o contexto no qual instituições, discentes, coordenações pedagógicas, professores e Estado estão alocados. Muitas direções não são sinônimos de caminhos perdidos ou confusos, mas são reflexos de possibilidades, oportunidades e liberdades que por meio da atividade avaliativa hodierna pode fazer com que o ensino jurídico saiba para quem e para o quê está de fato sendo colocado.

\section{AVALIAÇÃO: UMA VIA DE MÃO ÚNICA?}


A palavra avaliar parece trazer consigo uma essência de poder, algo que alguém com requisitos ou atribuições "especiais" impõe a outrem que é submetido a tal processo. Pensa-se em avaliação física, alimentar, na procura de um emprego, na obtenção da carteira de motorista ou na entrada para a universidade. Avalia-se para ter uma resposta, um resultado, um parecer, para saber o que "se aprendeu" efetivamente; avalia-se para entrar em determinado grupo ou para sair do mesmo.

No contexto geral da educação, a avaliação, enquanto um requisito para medir a aprendizagem, geralmente esteve ligada a essa captação das habilidades desenvolvidas ou não pelos alunos/as. É uma maneira de saber se os conhecimentos apreendidos são suficientes para o lidar com determinado desafio: como perceber o desempenho de determinado grupo em precedência a outro, se ocorreu o alcance dos objetivos e metas de ensino bem como auxiliar o professor na identificação de eventuais dificuldades dos discentes e ajudá-los no quer for preciso (KRAEMER, 2005).

Trata-se de uma intenção formativa ${ }^{3}$ diante do binômio ensino-aprendizagem uma vez que é através do processo avaliativo se estaria tendo dimensão da formação de determinado aluno/a, se a metodologia estaria adequada, se a expectativa depositada estaria em consonância com o que lhe apresentado e percebido. Mais do que isso, avaliar integra outras funções como o de diagnóstico diante desse momento de análise de habilidades e competências bem como uma função somativa, quando se permite mensurar, classificar, qualificar aquele aprendizado diante de um balanço final do que fora apresentado (KRAEMER, 2005).

Muito se fala da avaliação como algo de onde emana o status de aprovação ou reprovação. Parecem ser palavras como outras quaisquer, mas sob a perspectiva discente, tais colocações influenciam diretamente não só na situação escolar ou universitária, como para alguns reflete também da dinâmica familiar. Não deixa de ter um condão de julgamento visto que por vezes o aprendizado se faz mediante a declaração de uma nota, os percalços podem nem sempre ser visibilizados e com isso o que se tem como finalização de certo programa, matéria ou conteúdo pode não representar os ganhos efetivamente obtidos (GHIRARDI, 2012).

\footnotetext{
${ }^{3}$ Dentro desta perspectiva formativa pode-se auferir os erros e acertos dos alunos e fazer com que os mesmos tenham dimensão do que pode ser melhorado ou do que atingiu um certo grau de aprendizado satisfatório. Apesar de estar dentro da atribuição avaliativa, a priori, de responsabilidade do docente, nesta função abre-se espaço para um exercício de autorreflexão diante da diagramação dos avanços e retrocessos (OLIVEIRA, 2002).
} 
Embora haja toda esta gama de funcionalidades, e claro, um papel fundamental na formação de alunos, não se pode deixar de perceber que a avaliação em sua essência parece ser uma via de mão única quando se coloca que avaliar é uma competência do educador diante de determinado/a estudante. O sentido aparenta ser único, visto que é nas mãos do/a docente que está a palavra ou nota final e por consequência o "destino" de algum/a educando/a. O aprendizado fica restrito a uma só voz e a um único ato vindo de determinada pessoa que possui a habilitação necessária.

Lembra uma espécie de controle disciplinar que abrange tanto o espaço onde essa produção de disciplina e saber ocorrem como também quem o exerce. A vinculação entre professores/as e alunos/as parece ser uma relação de poder que pode ser espelhada na avaliação como instrumento de estímulo e mensuração de produções, recompensas ou punições. O/A aluno/a ali formado/a precisa estar em alinhamento com o que proferido e espera-se que tenha determinado comportamento compatível com o que lhe fora ensino. A direção vertical dessa análise não coloca o/a estudante como centro, mas como produto de decisões pedagógicas, nem sempre alinhadas com a realidade extramuros das salas de aula (FOUCAULT, 2008).

\footnotetext{
A existência de exames na escola é outro indicador desse tipo de poder. O exame, como já falado, faz de cada estudante um caso particular, sendo esse caso descrito, analisado, comparado, classificado e constantemente retreinado e normalizado. A aplicação de exames não garante que o aluno tenha de fato aprendido, já que na sociedade disciplinar, o "acerto" é digno de recompensa, neste sistema de troca e recompensa ininterrupto, nota-se que o aluno, sujeito da avaliação, busca por diversas vezes, aprender para obter essa gratificação, encontrada na escola como nota. O fim do aprendizado torna-se, então, a nota e não o conhecimento de fato (CRUZ; DE FREITAS, 2011, p.9-10)
}

Não se está colocando que deveria ocorrer o fim do método avaliativo, até porque avaliar faz parte da aprendizagem, na medida em que precisamos confirmar se os objetivos definidos no programa do curso/disciplina foram alcançados. Discutimos a ideia de avaliação como sinônimo de prova, de teste, em um momento único, isolado, deslocado no cotidiano construído no processo de aprendizagem. Ao lado disso, reconhecemos que ainda estamos diante de uma prática muito comum em diversos ambientes educacionais e ainda muito adotada por cursos, coordenações e professoras/es. O que se destacamos é que há um certo tempo percebemos que avaliar não pode ser o desfecho do ensino em si, e assim mantendo a compreensão de avaliação, legitimaríamos a afirmação de que a existência ou não de um 
aprendizado possa ser determinada única e exclusivamente pelo corpo docente, de modo que pensar em um sentido contrário seria fragilizar essas clássicas instituições.

Pensar o processo de aprendizagem como um movimento constante e que, assim como as viradas paradigmáticas, a todo tempo se renova diante das novas demandas, a avaliação pode tanto fazer jus à sua carga autoritária, como de outro modo coloca esse movimento enquanto uma espécie de atividade em grupo na qual avaliar não se resume ao professor e ao aluno, mas a toda conjuntura sistemática educacional em nome de uma transformação qualitativa. Isso porque avaliar não pode ser restrito a atribuição de notas, não pode trazer consigo apenas um sentido quantitativo do que se projeta e do que se capta. Se essa for a única forma de perceber o capital intelectual de um/a discente, coloca-se em xeque todos os verdadeiros objetivos das escolhas docentes, do corpo de coordenadores, institucionais e até mesmo estatais (DEMO, 1995).

Urge indagar a avaliação enquanto algo maior e mais versátil do que se tem, porque "ensinar exige consciência do inacabamento". Aquele que avalia não acaba seu trabalho em uma atribuição de nota, não esgota seu papel enquanto educador em um carimbo ou assinatura, aquele que recebe a nota também não centraliza seu papel enquanto aluno apenas dentro da sala de aula ou durante o horário e calendário letivo. O conteúdo nem sempre será esgotado visto que conhecimento é algo que muda a todo tempo, as dúvidas nem sempre serão respondidas porque em algum momento o questionamento desconhecido pode surpreender. Avaliar não encerra o ensino e não encerra a aprendizagem, mas ela pode auxiliar na troca de feedbacks de sujeitos que de maneira colaborativa e proporcionalmente importantes são atores principais do processo educacional (FREIRE, 1996).

Talvez tenha chegado um período no qual já não caiba mais encarar o ensino jurídico enquanto uma reprodução conteudista e colocar a avaliação como o grande momento da aferição da formação de um indivíduo. Pode ser que se faça mister quebrar esse elo hierárquico, não retirando o respeito para com professores/as, mas demonstrando que porventura o aluno tenha críticas a fazer diante dos exames a que fora submetido ou referente ao conteúdo ministrado e a metodologia utilizada. Por mais que se saiba que quem aplica uma prova possua, em tese, uma formação específica e o torna detentor de um arcabouço de conhecimento, permitir que o ato de avaliar ganhe outras direções, formatos, tempos, espaços e sujeitos, abre espaço para que haja uma reciclagem do processo cognitivo (DE MELLO, 2015). 
Ter mais de uma direção não implica que a avaliação passa a ser algo sem um propósito, sem um destino, sem uma razão de ser ou sem um destino específico. Entender o processo avaliatório como algo multidirecional é compreender que o ensino e a aprendizagem também não se resumem a apenas um único sentido. Esgotar essas atividades pode ser algo que assim como tantos outros ciclos apenas passe por uma renovação, por uma oxigenação diante das necessidades humanas.

\section{ENSINO JURÍDICO CONTEMPORÂNEO}

Apesar de muitos anos terem transcorrido, o ensino jurídico brasileiro ainda guarda consigo algumas referências do seu período imperial. Por muito tempo não havia cursos superiores no Brasil até como forma de não incentivar uma cultura intelectual e avanço da sociedade brasileira de modo a manter os laços portugueses. Era muito comum que os filhos de grandes latifundiários fossem até Portugal para estudar Direito e retornarem não só com o diploma, mas também com o prestígio que aquele título conferia (SILVA, 2012).

De um modo ou de outro, ser bacharel em Direito continha um status social relevante, era uma forma de conseguir cargos políticos, negociar dentro dos mercados e conseguir a influência social necessária em um país no qual historicamente, muito antes do ser, era preciso analisar o ter. Cidades como Olinda, São Paulo e Recife depois se tornaram lugares de renome em razão de seus tradicionais cursos jurídicos, já em terras brasileiras mas sempre guardando um pé no continente europeu. O curso de Direito no Brasil costumava não atender as realidades locais, parecia algo dissociado do local no qual era instalado e por quem e para quem era destinado, mesmo com a ampliação da oferta de ensino subsequente, alguns problemas se fizeram presentes visto a questão da quantidade ${ }^{4}$ poderia influenciar diretamente na qualidade educacional e profissional (SILVA, 2012).

No século XXI, mesmo após muitos avanços, é fácil identificar que o ensino jurídico brasileiro tende a preservar em sua base o caráter positivista do Direito. Metodologias ainda em sentidos unidirecionais, sem muita abertura para críticas, participações discentes, aulas enraizadas na forma expositiva, legalista, dogmática, resistência à inserção da

\footnotetext{
${ }^{4}$ A rápida proliferação dos cursos jurídicos no Brasil pode até vir respaldada em uma espécie de democratização da educação e por conseguinte, do ensino superior. Todavia, a forma como o ensino jurídico veio sendo encarado a nível nacional resvala não só na abertura desenfreada de cursos particularidades como também na dúvida de como manter uma qualidade de ensino-aprendizagem diante de uma infinitude de propostas pedagógicas. O que deveria ser tipo como finalidade precípua, parece ter sido tornado em um interesse mercadológico no qual alunos, professores, coordenadores e instituições saem perdendo, nem que seja em alguma medida (HIRONAKA, 2008).
} 
interdisciplinariedade, as posições de professores, alunos e corpo pedagógico tendem a se manterem inertes e não se relacionarem muito, prefere e a neutralidade do que o levantar de opiniões e senso crítico (MESQUISA, 2005).

Claro que diante do mundo globalizado em que se vive - as novas demandas sociais, a ingerência tecnológica das relações e no ensino, a constatação de que as ciências conversam entre si e que esse diálogo se faz necessário - percebeu-se que já não cabia mais aceitar e perpetuar tradições tão regressivas dentro do ensino jurídico. Por óbvio, esses traços ainda existem e acompanham os cursos em andamento e os que irão abrir. Contudo, certo é que há um movimento de atualização, aceitação e de proximidade com os sujeitos do ensino do Direito no Brasil. Não se pode ainda falar em quebrar de elos tão antigos, mas o fragilizar desses ligamentos e a identificação de novas colaborações faz do ensino jurídico uma mutação constante em uma sociedade em frequente movimento.

Essa nova faceta do ensino jurídico tende a primar por um impacto público da educação no ensino superior. Não se quer apenas formar bacharéis ou advogados/as, mas antes de tudo cidadãos, alunos conectados no sentido mais humano possível das verdadeiras salas de aula que a vida proporciona. Profissionais capazes de alinhar teoria e prática, que possam entender que o ensino não resumo a aprendizagem, mas que mister é a presença da pesquisa e da extensão para uma formação de um todo mais conciso (VIEIRA, 2012).

É preciso entender o Direito dentro de um movimento dialético e, por conseguinte, o ensino jurídico da mesma forma. A complexidade dessa dinâmica não está no sentido de dificuldade, mas de expansão, de multiplicidade, de profundidade. $\mathrm{O}$ ensino do Direito não se resume aos códigos, é também fruto das matérias básicas, das propedêuticas, da pesquisa de campo, da extensão, do diálogo com a coletividade. É perceber que o Direito não é algo estático, resumido a um conjunto de normas, mas que diz respeito aos grupos, classes, sujeitos, localidades nas quais a pluralidade precisa ser respeitada, sob a ameaça de que o Direito se mantenha, no século XXI, como uma ferramenta que invisibiliza os que não estão nas esferas de poder, o obstaculariza a concretização de políticas públicas e de direitos fundamentais. Questionar o que é o Direito na contemporaneidade é responder não de modo inequívoco, mas permitir que haja respeito às subjetividades, para que essa ciência não se mantenha mais tão distante dos interesses de quem realmente são seus destinatários (LYRA FILHO, 2017). 
[...] não é necessário um modelo único de faculdade de Direito. É preciso, não obstante, que se exponham as opções adotadas, suas implicações e suas justificativas. Nesse sentido, o processo regulatório deve facilitar a contraposição de alternativas e a explicitação de escolhas. Deve-se ter clareza, em última instância, sobre a visão de Universidade subjacente a essas escolhas, de maneira que os meios adotados para a configuração dos cursos jurídicos não sejam supérfluos ou considerados válidos em si mesmos: é fundamental que sejam aptos a promover um objetivo maior (GHIRARDI et al, 2020, p. 6)

Na tentativa de romper com o imobilismo tradicional dos cursos jurídicos, cada vez mais temos percebido a troca das posições de alunos e professores diante de novas formas de lecionar e troca de conhecimento. Flexibilizar posições permite uma maior liberdade acadêmica e a construção conjunta tanto do ensino como da aprendizagem. Simulados, visitas de campo, rodas de conversa e seminários, por exemplo, permitem esse deslocamento de arranjos nos quais o papel do docente não implica a retenção de um conhecimento absoluto e estanque, é possível que o discente também venha a ensiná-lo sobre algo de sua vivencia, sua realidade ou mostrar um ponto de vista até então não explorado. É preciso que o ensino jurídico seja mais sensível, menos controlador, mais colaborativo e integrativo e menos excludente (PIMENTA; ANASTASIOU; CAVALLET, 2003).

\begin{abstract}
Sob essa perspectiva, a relação entre professores e alunos não é mais vista como vertical, mas forma uma espécie de grupo de trabalho em que o posicionamento dos estudantes deixa de ser meramente passivo. $\mathrm{O}$ vínculo entre todos os participantes envolvidos e o papel dos docentes ou instrutores muda radicalmente, pois, de detentores e transmissores de saber, passam a ser facilitadores do aprendizado, em uma relação horizontal e coletiva, enquanto os discentes passam a desenvolver uma relação cooperativa com seus pares, configurando uma equipe empenhada em determinado objetivo, e não mais passivos nem concorrentes ou justapostos para receber um produto final (FERFEBAUM; LIMA, 2020, p.152)
\end{abstract}

Um exemplo de como nos últimos 10 anos há mudanças significativas no ensino jurídico, as quais dialogam com as afirmações acima delineadas, e contribuem para fissurar referida rigidez do ensino jurídico, apontamos a inserção dos métodos adequados em resolução de conflitos vem não só para auxiliar na mudança cultural da adjudicação e do litígio como matrizes da prática jurídica, mas chegam demonstrando que para além de uma demanda, existem interesses, pessoas e sentimentos envolvidos. É o poder e valor da escuta, das sessões privadas, do rapport, do restabelecer a comunicação e o diálogo que se pode ganhar muito mais, e não estar-se-á falando no sentido monetário. Demonstrar na sala de aula que o Direito não é apenas o triangularizar de relações, mas também o permitir de olhares e a permuta de circunstâncias e colocações provoca o entendimento de uma ciência mais próxima 
de satisfações do que necessariamente de procedências processuais (DE CASTRO OLIVEIRA; PRUDENTE, 2019).

Ainda no sentido de pontuarmos mudanças em andamento no ensino jurídico, reconhecemos ser cada vez mais frequente a presença da tecnologia no exercício das profissões jurídicas deste mundo pós-globalizado. A inteligência artificial e softwares avançados sendo utilizados e aprimorados em tribunais e plataformas de comunicação oficial acabam fazendo parte das ferramentas de trabalho desse jurista contemporâneo no qual, a dinâmica, o movimento e capacidade de adaptação tornam esse individuo mais versátil tanto para o mercado de trabalho como para a vida em sociedade. São mudanças essas levadas para as discussões entre corpos discentes e docentes na tentativa de aproximar o ensino do seu verdadeiro campo de atuação, falar sobre tecnologia e Direito não é falar sobre o amanhã, mas sobre o hoje (FEFERBAUM; LIMA, 2020).

Do que adianta ter uma matriz pedagógica alheia aos fatos externos? Alheia às novas profissões, demandas, relações ou mecanismos de comunicação? Sabemos ser necessário inserir não só a tecnologia em si, mas o debate sobre seu uso dentro do mundo jurídico, impactos positivos e negativos, visões de setor público e privado, falar de democratização do uso da internet, desigualdades sociais e acesso à educação são pontos de partida e ao mesmo tempo destinos finais de questões que precisam ser levadas para o ambiente universitário.

Se o meio no qual o ensino jurídico insere-se está mudando, nada mais razoável que tudo e todos que o compõem possam olhar para o que está posto e definido e refletir o que está em consonância ou não com esses novos desafios. Se tal ponderação não fora atentada, continuar-se-á perpetuando uma metodologia de ensino superior colonial e extremamente dogmática. Se tudo está se movendo, manter professores, alunos, coordenadores e instituições inertes é para além de prejudicar o binômio ensino-aprendizagem, é prejudicar a formação individual de uma pessoa. Sabendo que a educação ainda hoje é, senão a principal chave de oportunidades e transformadora de realidades em meio a um país tão marcado pelas suas fissuras sociais, não realizar ou ao menos tentar esse movimento pode aumentar ainda mais as distâncias na concretização de garantias fundamentais.

Formatos das salas de aulas, participações dos alunos, uso de metodologias ativas e integrativas, a comunicação entre discentes e o corpo pedagógico, alinhamento teórico e prático, aulas que incentivem a criticidade e construção de um senso mais humano e as formas de avaliação são alguns dos componentes do ensino jurídico que passam por uma verdadeira 
transformação na última década. Passam não só porque em determinado momento parecem não atenderem mais às exigências do ensino pós-moderno ${ }^{5}$, como também parecem desconhecer quem são os sujeitos que fazem parte da dinâmica educacional. Se o ensino jurídico não estiver alinhado a quem the opera, quem lhe ministra, quem lhe coordena e a quem lhe é destinado, estar-se-á diante do esvaziar de políticas públicas, iniciativas privadas e materialização de núcleos primordiais do desenvolvimento como liberdade ${ }^{6}$.

\section{MULTIDIREÇÕES AVALIATIVAS: e possível UM ENSINO JURÍDICO MAIS QUALITATIVO?}

Já fora suscitada a relevância de se entender o ensino jurídico contemporâneo como algo dinâmico, que se movimenta e movimenta o que está ao seu redor (sujeitos envolvidos, matérias, metodologias e concepções de espaciais de sala de aula etc). Movimentar é mais do que direcionar energia e proporcionar dinamismo, é possibilitar que o imobilismo antes tido ceda lugar a uma junção de forças em prol de uma proposta de ensino mais condizente com o mundo hodierno. Movimentar pode ainda ser sinônimo de atualização, de sintonia e de possibilitar a escuta no lugar exclusivo da fala, é entender o objeto de estudo além do tecnicismo necessário, além do latim jurídico e além dos arcabouços normativos. Movimentar nesse novo ensinar o Direito na sociedade contemporânea, é fazer das escolhas, vias de direcionamento e não mais, normas de conduta.

A avaliação, assim como outros componentes do ensino jurídico, precisa e deve ser colocada enquanto um instrumento e não mais um fim no processo de aprendizagem. $\mathrm{O}$ resultado da avaliação deve ser uma métrica hábil a aferir o apreendido pelo/a discente, reconhecendo a importância, de objetivamente: perceber se se agregou informação de qualidade ao cabedal inicial do/a discente; verificar se ficou claro que o conhecimento não se esgota ali, que o pensamento crítico e que a depuração dos fatos e conteúdos ao longo do tempo compõe o aprendizado; compreender que o desempenho do estudante não é o único responsável pelo sucesso ou insucesso de uma proposta metodológica etc.

\footnotetext{
${ }^{5}$ A proposta de um ensino dentro do paradigma pós-moderno vai ao encontro da fluidez e volaticidade características desse panorama. Aprender e ensinar não podem mais ser estaques, não podem imobilizar os sujeitos que ali atuam ou que ali são atingidos de alguma forma. É dentro deste movimento que se espera um ensino superior mais adaptável e que consiga transitar entre o ser e o dever ser (GERVASONI, 2017).

${ }^{6} \mathrm{~A}$ oferta de um ensino superior alinhado com as necessidades sociais e em consonância com matrizes pedagógicas que potencializam e incentivam habilidades e competências de todo o corpo educacional, não só cria oportunidades como também dá liberdade e autonomia para que esses indivíduos não só perpetuem o que fora aprendido e ensinado, como também para que se tornem sujeitos de transformação no contexto ao qual estão inseridos (SEM, 2018).
} 
Outro aspecto que merece nossa atenção é que a avaliação deve ser implementada também para os/as docentes, para o corpo pedagógico, para as próprias instituições, quem sabe até para a própria sociedade local, dos arredores daquele centro de ensino, vez que é ali o campo prático mais próximo das instituições.

Avaliar em multidireções os sujeitos, de formas diferentes, em tempos e espaços diversos pode viabilizar um ensino mais próximo das reais necessidades de todos o que compõem a dinâmica de ensino, pode ajudar na composição de um ensino jurídico mais qualitativo não só porque se dará voz a quem queira contribuir, como se permitirá uma espécie de reciclagem e atualização em um curso tradicionalmente alheio às práticas colaborativas.

\footnotetext{
A prática da avaliação passa também pelo processo de democratização da escola. É imprescindível que haja o envolvimento e participação de todos os segmentos da escola: direção, professores, funcionários, alunos, pais, comunidade na elaboração de um plano de trabalho, no seu acompanhamento e na avaliação de seus resultados. Esse procedimento dará a escola legitimação política à sua ação educativa (BETINI, 2009, p. 49)
}

Focar a avaliação não só na direção da formação mais formal e burocrática, inerentes à vivencia jurídica, mas sim, procurar a qualidade social dessa avaliação faz com que a concepção de aprendizagem saia do papel e alcance o meio ao qual aquele aluno está inserido. É buscar uma espécie de função social desse ensino e dessa aprendizagem para além do que estará contido em diplomas e certificados. O que mais o aluno é além de aluno? O que mais ele pode vir a se tornar ou quem ele já é dentro do seu espaço de vivência e atuação? Qualidade social no mecanismo avaliativo é expandir que o aprendizado por si só também não é unidirecional, se faz das mais diversas formas, portanto, se aprender é algo múltiplo, por qual razão avaliar deveria ser uma ação padrão a ser aplicada nos discentes? (DALBEN; ALMEIDA, 2015).

Apontamos, ainda, a importância da forma autoavaliativa como mecanismo de reflexão de desempenho e papéis executados. Apesar das universidades e centros de ensinos ainda representarem um espaço com certa hierarquia, possibilitar a autoavaliação das instalações, das didáticas, dos professores, da comunicação pedagógica e dos discentes ajuda em muito que os problemas internos sejam compartilhados e soluções sejam buscadas de forma conjunta. Não são invasões de espaços, mas exercícios de autorreflexão e autoanálise de quem está do lado de dentro vivenciado toda a rotina educacional. Fazer com que alunos 
avaliem professores é mostrar que é preciso haver liberdade e autonomia para tal movimento de modo que esses sujeitos venham a demonstrar dificuldades, críticas e colaborações. Não é o fato de estarem, em tese, em um local de subordinação que suas vozes não devem ser ouvidas (GOULARTE; RUMPEL, 2017).

Levando em conta a grande quantidade ${ }^{7}$ de cursos jurídicos existentes no país, para além de um controle externo realizado pelas autoridades competentes permitir que esses mesmos cursos se avaliem, faz com que se tenha mais dimensão do perigo de quantificar demais o ensino jurídico de modo a comprometer sua qualidade. Permite conhecer quais as dificuldades que professores realmente estão tendo para além do ato de ministrar aulas baseadas em planos de ensino. O plano de fato é uma bússola com as coordenadas a serem estabelecidas para as aulas subsequentes, mas se este não estiver sendo suficiente ou estiver alheio à debates que os alunos precisam ter acesso, dar-se-á por prejudicado o esforço na construção deste roteiro.

A autovaliação institucional possibilita ainda um parâmetro diante da oferta de cursos jurídicos de rede pública e da rede privada, sendo viável o dimensionar das proximidades e distâncias entre cada uma. As necessidades das universidades públicas podem não ser as mesmas das privadas e assim por diante, se reitores e coordenadores não souberem olhar e captar suas fraquezas e seus pontos fortes, como promover uma revolução educacional de qualidade? É por meio da implementação de autoavaliações que se faz pertinente e viável mensurar quantitativa e qualitativamente até onde o ensino consegue chegar.

\begin{abstract}
A autoavaliação é uma excelente ferramenta para despertar a reflexão sobre seu próprio desempenho, a consciência sobre o próprio aprendizado e a percepção da própria imagem. Já a avaliação por pares, na qual um aluno avalia o colega, é uma ferramenta que desenvolve a empatia, a cordialidade, a capacidade de dar e receber feedbacks honestos e gentis [...] Ao sensibilizá-los sobre a importância das pessoas na vida profissional, por exemplo, para o sucesso de uma atividade em equipe, tornar-se-á desafiador cumprir essa tarefa. Além do mais, para o ser humano importam o olhar e a opinião do outro sobre nós mesmos (FEFERBAUM, 2020, p. 277-279)
\end{abstract}

Dentro da avaliação por pares, pode-se ainda colocar que por vezes os alunos tendem a conhecer mais a si mesmos do que alguns professores. A rotina, as conversas e a convivência extra sala, faz com que estudantes acabem entendendo mais quem são aquelas pessoas para além da condição de alunos. Eventuais adversidades na captação do conteúdo ou dificuldades

\footnotetext{
${ }^{7}$ No ano de 2017 existiam cerca de 1.203 cursos de Direito no Brasil, o que torna o país como o que lidera o maior número de cursos jurídicos do mundo (FGV, 2020).
} 
em determinado assunto, por vezes é mais compartilhado com o colega ali do lado do que com o professor daquela matéria. Logo, a avaliação por pares é uma ferramenta que discentes podem utilizar para aproximação desses alunos e eventualmente oferecer-lhes o apoio pedagógico necessário.

Destacamos que ainda que remanesça a presença nos cursos de Direito filhos/as de advogados renomados, de famílias com carreiras jurídicas e de grande influencia politica e econômica, o que não e' um problema apenas a constatação de alguns laços e privilégios históricos, hoje, de fato, podemos dizer que há uma certa democratização do acesso à educação superior, e no caso dos cursos jurídicos, a composição das turmas pode ser bem plural no sentido de ter alunos das mais diversas realidades sociais.

A autovaliação, dentro desse contexto, permite que discente possam explanar ou sinalizar pontos fortes e fracos de seu aprendizado levando em conta o contexto ao qual estão inseridos. É um momento único e próprio de autoanálise na qual por mais que a universidade se faça presente na vida desses estudantes, nem sempre ela conseguirá chegar nas fissuras que vão além das salas de aula.

Ainda no sentido proposto, falar de autoavaliação aplicada para o próprio corpo dos locais de educação, e no caso, jurídica, não é apelas avaliar por avaliar, mas pensar em comum esses testes, exames, entrevistas, questionários ou rodas de conversas podem ser realizadas. Quais questionamentos devem ser feitos, quais os tipos de respostas esperadas e as não esperadas, o anotar das contribuições e setorizar prioridades, o momento no qual a comunidade entra nesse diálogo e quem conduz esse debate são alguns dos pontos que faz com que a autoavalização além de mais robusta, seja também o alicerce para as mudanças desejadas (GOULARTE; RUMPEL, 2017).

Nesse sentido, podemos ainda apresentar como uma das soluções para o ensino jurídico, e demais ciências, a avaliação por observação como manejador dessas multidireções apresentadas. Nem sempre aquilo que está inserido nas respostas das provas tradicionalmente escritas exprime o real aprendizado ou as reais dificuldades de um aluno. Avaliar por observação não é apenas analisar composições e comportamentos corporais, é prestar atenção em sinais, em expressões, em como um discente se sente ou não confortável com determinado assunto ou determinado professor, é saber se o aluno "aceita uma opinião sem questioná-la" ou se "o estudante analisa uma situação por outra perspectiva em relação aos demais estudantes" (FEFERBAUM, 2020). 
Os silêncios, os não-ditos são formas legítimas e reais de comunicação, perceber as singularidades das turmas, as sutilezas das demandas, as entrelinhas das relações compõem o cenário atual do processo de aprendizagem. A troca de uma direção de avaliação escrita para uma avaliação observada pode conferir àquele resultado ou àquelas anotações mais proximidade com as demandas educacionais, sociais e pessoais de todos os sujeitos ali inseridos. O observar também pode ser feito de alunos para com professores, de alunos para com corpo pedagógico, de funcionários para com coordenadores e reitores, da comunidade para com as instituições de ensino.

O ensino jurídico no século XXI precisar sentir e dar sentido ao seu papel na construção de personalidades, profissões e de cidadania diante desse mundo complexo, diverso, desigual e, também, repleto de potencial para ressignificar e (re)construir. Falamos muito que agora o acesso à educação superior aumentou, que a oferta de cursos, presença de professores e uso de diversas metodologias se fizeram e estão se fazendo presentes no cotidiano dos/as estudantes.

Por outro lado, em nada adianta ter tantos recursos e tantas portas se o processo de aprendizagem não é eficiente, não olha para quem faz parte do ambiente de ensino e de aprendizagem ou não consegue captar conquistas e problemas na construção do conhecimento. Avaliar em um sentido multidimensional no ensino jurídico hodierno é trazer qualidade para um curso que historicamente quantifica quem deve lecionar, quem deve aprender e como estes devem se portar.

\section{CONCLUSÃO}

Tentar modificar matrizes de ensino e aprendizagem de dentro para fora não é uma tarefa fácil. É um exercício de autorreflexão de um ambiente que nem sempre aceita críticas, por vezes tende a querer que as posições dos seus sujeitos seja estanque e em alguns casos, vê na realidade social na qual está inserido um desafio a ser enfrentado no que tange conciliar prática e teoria.

O ambiente de ensino superior no Brasil vivencia hoje reconfigurações de uma sociedade na qual se a educação ainda é a resposta e solução para as mazelas, se faz justo e pertinente que a primeira ou uma das primeiras revoluções a serem feitas, consista na realização de sua própria esfera. 
Tratar de avaliação na contemporaneidade é perceber que hoje, fazer essa aferição em um só sentido é enganar toda uma conjuntura universitária que está intensamente conectada. As respostas para uma educação superior de qualidade não estão na nota dez ou na nota zero de determinado aluno, no carimbo ou mesmo na assinatura do professor ao conferir tal mensuração. É falho acreditar que para avaliar bastaria um tripé formado por um aluno, um discente e perguntas de um conteúdo dogmático com viés positivista, como acontece no ensino jurídico.

Não que todas as ciências vivenciem esta crise na matriz avaliativa, mas em especial nos cursos de Direito, luta-se contra uma cultura colonial que mais provoca regressão do que avanço. Já não há mais espaço para uma perpetuação de traços no quais o ensino jurídico é classista, alheio às demandas sociais e vê na figura do aluno apenas um advogado em potencial.

A palavra para esse novo paradigma jurídico é mudança, é movimento, é trazer um pouco de desordem para realinhar o que se tinha como correto. É fazer com que sujeitos, espaços, conteúdos e instituições conversem e saibam onde, como, quem e para o quê devem atuar. Se o Direito contemporâneo não se resume mais à formação advocatícia, entender o ensino jurídico em uma magnitude mais ampla e profunda, se faz bem mais razoável e sensato.

Avaliar em multidireções é justamente quebrar essa tendência estanque na qual só uma pessoa tem vez, espaço e voz. É quebrar a ideia na qual para avaliar precisa de dois sujeitos ou de papel e caneta. É entender que avaliar qualitativamente é investir no cerne da educação superior, é concatenar ideias, sugestões, pontos críticos, é revisar o papel das instituições de ensino na pós-modernidade.

Compreender que o aprendizado não se faz apenas mediante anotações ou dentro do espaço da sala de aula, é possibilitar que a formação educacional seja vivenciada extra muros e de forma dinâmica. É dentro de uma avaliação mais próxima, mais sensível e mais solidária que se pode ter para além dos escopos jurídicos, a busca da dignidade da pessoa humana. É fazer da relação de ensino aprendizagem não mais momentos efêmeros e sem sentido, mas sim, que digam respeito aos instantes dos encontros que vão além de qualquer nota e de qualquer aprovação.

\section{REFERÊNCIAS}


BETINI, Geraldo A. Avaliação institucional em escolas públicas de ensino fundamental de Campinas. 2009. 394f. Tese (Doutorado) - Universidade Estadual de Campinas, Faculdade de Educação, Campinas, 2009. Disponivel em http://repositorio.unicamp.br/handle/REPOSIP/251722. Acesso em 26 de dezembro de 2020

CRUZ, Priscila Aparecida Silva; DE FREITAS, Silvane Aparecida. Disciplina, Controle Social e Educação Escolar: um breve estudo à luz do pensamento de Michel Foucault. Revista Levs, v. 7, n. 7, 2011. Disponivel em: https://revistas.marilia.unesp.br/index.php/levs/article/view/1674. Acesso em 20 de dezembro de 2020

DALBEN, Adilson; ALMEIDA, Luana Costa. Para uma avaliação de larga escala multidimensional. Estudos em Avaliação Educacional, v. 26, n. 61, p. 12-28, 2015. Disponivel em: http://publicacoes.fcc.org.br/index.php/eae/article/view/3140/2954. Acesso em 25 de dezembro de 2020

DE CASTRO OLIVEIRA, Gustavo Paschoal Teixeira; PRUDENTE, Ângela Maria Ribeiro. A conciliação como uma nova perspectiva no ensino jurídico à frente da formação adversarial das profissões jurídicas. Humanidades \& Inovação, v. 6, n. 13, p. 230-244, 2019. Disponivel em: https://revista.unitins.br/index.php/humanidadeseinovacao/article/view/1634. Acesso em 23 de dezembro de 2020

DE MELLO, Laís Pereira. Avaliação de aprendizagem em métodos participativos. In: Ensino Jurídico e formação docente. Brasília: UNICEUB, 2015. Disponivel em: https://repositorio.uniceub.br/jspui/bitstream/235/7335/1/Ensino_Juridico_Formacao_Docente .pdf. Cesso em 20 de dezembro de 2020

DEMO, Pedro. Avaliação qualitativa: polêmicas do nosso tempo. Campinas, SP: Autores, 1995.

FEFERBAUM, Marina. Metodologias ativas em direito: guia prático para o ensino jurídico participativo e inovador. Organizadores: Marina Feferbaum, Guilherme Forma Klafke. São Paulo: atlas, 2020

; LIMA, Stephane HB. Formação jurídica e novas tecnologias: relato de uma aprendizagem experiencial em direito. Revista Opinião Jurídica (Fortaleza), v. 18, n. 28, p. 145-162, 2020.2 Disponivel em: https://periodicos.unichristus.edu.br/opiniaojuridica/article/view/2740. Acesso em 24 de dezembro de 2020

FGV, Fundação Getúlio Vargas. Exame da Ordem em Números. Edição 2020. $4^{\mathrm{a}}$ Edição. Disponível em: https://www.jota.info/carreira/brasil-tem-mais-de-1-500-cursos-de-direitomas-so-232-tem-desempenho-satisfatorio-14042020, Acesso em 25 de março de 2021

FINCATO, Denise Pires. A pesquisa jurídica sem mistérios: da pesquisa à banca. 2 ed. rev e amp. Porto Alegre: Sapiens, 2014. 
FOUCAULT, Michel. Vigiar e Punir. Trad. Raquel Ramalhete. Petrópolis: Vozes, 2008.

FREIRE, Paulo. Pedagogia da Autonomia: Saberes necessários á prática educativa. São Paulo: Paz e Terra, 1996. (Coleção Leitura).

GERVASONI, Tássia Aparecida. Estado e Direito em trânsito na pós-modernidade. Florianópolis, Santa Catarina: Empório do Direito, 2017.

GHIRARDI, José Garcez. O instante do encontro: questões fundamentais para o ensino jurídico. 2012. Disponivel em: https://bibliotecadigital.fgv.br/dspace/handle/10438/10303. Acesso em 20 de dezembro de 2020

et al. Visões de universidade nas críticas ao ensino jurídico brasileiro.

2020. Disponivel

em:

https://bibliotecadigital.fgv.br/dspace/bitstream/handle/10438/28633/artigo_visoes_de_univer sidade_nas_criticas_ao_ensino_juridico_20160315.pdf?sequence $=1 \&$ is Allowed $=\mathrm{y}$. Acesso em 23 de dezembro de 2020

GOULARTE, Raquel Da Silva; RUMPEL, Leíze Barbo Nemitz. A autoavaliação institucional no contexto do instituto federal farroupilha: histórico, desafios e perspectivas. $2017 . \quad$ Disponivel em: https://repositorio.ufsc.br/bitstream/handle/123456789/179313/101_00643\%20-

$\% 20$ ok.pdf?sequence $=1$. Acesso em 25 de dezembro de 2020

HIRONAKA, Giselda Maria Fernandes Novaes. Ensino do direito: dos primórdios à expansão pelo setor privado. In: Ensino Jurídico e a produção de teses e dissertações. São Paulo: Edgard Blucher, 2008. 146 p.

KRAEMER, Maria Elisabeth Pereira. Avaliação da aprendizagem como construção do saber. $2005 . \quad$ Disponivel em: https://repositorio.ufsc.br/xmlui/bitstream/handle/123456789/96974/Maria\%20Elizabeth\%20 Kraemer\%20-

$\% 20$ Avalia $\%$ c3\%a7\%c3\%a3o\%20da $\% 20$ aprendizagem $\% 20$ como $\% 20$ con.pdf?sequence=3\&i sAllowed=y. Acesso em 20 de dezembro de 2020

LYRA FILHO, Roberto. O que é direito. Brasiliense, 2017.

MESQUITA, Márcio Satalino. O positivismo jurídico como fundamento da educação do bacharel em direito: a concepção do objeto como condicionante do modo de ensino. 2005. Disponivel em: https://repositorio.ufscar.br/handle/ufscar/2788. Acesso em 22 de dezembro de 2020.

OLIVEIRA, Gerson Pastre de. Avaliação formativa nos cursos superiores: verificações qualitativas no processo de ensino-aprendizagem e a autonomia dos educandos. OEI-Revista Iberoamericana de Educación. Disponível em:. Acesso em, v. 15, 2002. Disponivel em: https://www.researchgate.net/profile/Gerson_Oliveira5/publication/306064679_AVALIACA O_FORMATIVA_NOS_CURSOS_SUPERIORES_VERIFICACOES_QUALITATIVAS_N O_PROCESSO_DE_ENSINO- 
APRENDIZAGEM_E_A_AUTONOMIA_DOS_EDUCANDOS/links/57ad713f08ae0932c97 5083f/AVALIACAO-FORMATIVA-NOS-CURSOS-SUPERIORES-VERIFICACOESQUALITATIVAS-NO-PROCESSO-DE-ENSINO-APRENDIZAGEM-E-A-AUTONOMIADOS-EDUCANDOS.pdf. Acesso em 20 de dezembro de 2020

PIMENTA, Selma Garrido; ANASTASIOU, Léa das Graças Camargos; CAVALLET, Valdo José. Docência no ensino superior: construindo caminhos. Formação de educadores: desafios e perspectivas. São Paulo: UNESP, p. 267-278, 2003. Disponivel em: https://esmec.tjce.jus.br/wp-content/uploads/2016/02/Texto-1-Barbosa.pdf\#page=256. Acesso em 22 de dezembro de 2020

SEN, Amartya. Desenvolvimento como liberdade. Editora Companhia das letras, 2018.

SILVA, Vânia Regina de Vasconcelos Reis e. Os processos de ensino e de aprendizagem no curso de Direito. Tese de Doutorado. Universidade de São Paulo. 2012. Disponivel em: https://teses.usp.br/teses/disponiveis/59/59137/tde-10102013-160100/pt-br.php. Acesso em 21 de dezembro de 2020

VIEIRA, Oscar Vilhena. Desafios do Ensino Jurídico num mundo em transição: o projeto da Direito GV. In: Ensino do Direito para um mundo em transformação. Organizadores: Marina Feferbaum, José Garcez Ghirardi. 2012. Disponivel em https://bibliotecadigital.fgv.br/dspace/handle/10438/10304. Acesso em 23 de dezembro de 2020 